\title{
Disposiciones afectivas y cambio social
}

\author{
Vanesa SAIZ ECHEZARRETA*
}

Propuesto: 27 de Abril de 2012

Evaluado: 5 de mayo de 2012

Aceptado: 14 de mayo de 2012

(Abstracts y palabras clave al final del texto)

\section{INTRODUCCIÓN 1}

En el área de investigación sobre comunicación y cambio social se trabaja sobre una serie de presupuestos compartidos, valores, esperanzas y deseos cuyo horizonte más claro es la aspiración a la justicia social. Estos presupuestos no están suficientemente explicitados, ni debatidos y su aceptación implica, entre otros aspectos, una noción de cambio social de corte teleológico que podría reforzar una narración y una lógica moderna, incluso desarrollista. En muchos de los trabajos adscritos a este campo, el cambio social implica una especie de avance en términos lineales, que persigue la consecución de ideales - muchas veces poco matizados - como la solidaridad, la igualdad, la emancipación, la compasión, el diálogo, la participación, etc. Es evidente que el cambio social, tal y como se concibe en la tradición sociológica, no presupone una orientación axiológica predefinida; sin embargo, en este área de investigación el concepto opera como consigna, al poner en valor la "justicia social" como horizonte.

Es importante criticar y reparar esta inconsistencia teórica, pero no es nuestro objetivo señalar el riesgo de esta falta de explicitación en términos generales, lo abordaremos desde una aproximación teórica al análisis y a la crítica de las emociones y los sentimientos que se activan en la investigación sobre el cambio social, específicamente, aplicado a las acciones colectivas que persiguen un ideal de justicia social. Al igual que sucede en otras áreas de interés, la investigación sobre la acción colectiva en la lucha contra la pobreza y a favor de la justicia social y los derechos humanos debe prestar atención al repertorio emocional implicado y funda-

* Facultad de Periodismo UCLM

1 Agradezco a Wenceslao Castañares y a Cristina Peñamarin su lectura atenta y sus aportaciones, sobre todo, de orden epistemológico que han enriquecido y fortalecido este trabajo. También han sido relevantes los comentarios de los evaluadores ciegos del artículo y la sugerencia de Ana F. Viso sobre la equiparación en esta área de estudio entre cambio social y justicia social. 
mentar su análisis con un modelo teórico pertinente, para no incurrir en la construcción de conceptos comodín y en su utilización indefinida.

No obstante, el esfuerzo por incorporar la reflexión sobre la dimensión afectiva no se restringe a un planteamiento teórico sino que atañe además a su lugar de enunciación, esto es, a la posición afectivo-axiológica adoptada por el investigador. En este sentido, el ideal compartido sobre "justicia social" y la vocación de transformación política es un referente implícito que condiciona la definición y el abordaje de sus objetos de estudio. Aunque este lugar de investigación puede suponer ciertas limitaciones - sobre todo, cuando no se equilibra adecuadamente con la distancia que reclama toda investigación científica-, también es cierto que esta posición afectivo-axiológica implica — como propone Bajtin $(1997,70)$ — una "atención amorosamente interesada" hacia nuestros objetos teóricos y analíticos ${ }^{2}$. Compartir la esperanza y el deseo de componer una mejor versión del mundo que habitamos es un espacio común que presupone un hacer investigador orientado por tales afectos.

Sin embargo, la implicación afectiva, política y ética no sustituyen el rigor científico y, hasta el momento, el corpus analítico y los estudios empíricos al respecto son todavía insuficientes, puesto que no se ha producido en este campo una discusión teórica amplia sobre las emociones. Para que ésta tenga lugar, es necesario huir de los conceptos sostenidos tan sólo en las concepciones propias del "sentido común"3 y en las perspectivas puramente ideológicas, como sucede en buena parte de la literatura especializada en comunicación y cambio social.

Este trabajo surge de una reflexión sobre los lugares comunes en torno a las emociones colectivas que permanecen incuestionados en buena parte de la investigación en este ámbito. Plantearemos una propuesta teórica que rechaza la concepción apriorística y naturalizada de las emociones como fenómenos espontáneos, instintivos, irracionales, no dependientes de lo social y, en general, ingobernables. También cuestionaremos el presupuesto de que existen emociones buenas, positivas, incluso justas por sí mismas; una concepción que suele estar en la base de la utilización de la compasión, la solidaridad o la empatía como recurso argumental. Habitualmente, se moviliza como marco de interpretación el narcisismo contemporáneo (Sennet, 2002), que defiende un sentimentalismo en el que la experiencia y expresión de una emoción auténtica y sincera - básicamente compasiva - caracteriza al sujeto y sirve para justificarle.

En esta línea, la comunicación debe servir para educar y sensibilizar, lo que se traduce en movilizar emociones amables y compartidas cuyos mecanismos de activación y funcionamiento nunca se explican. El repertorio emocional analizado se limita a la solidaridad, la compasión, la culpabilidad y, en algún caso, fenómenos

2 Sólo esta atención amorosa "es capaz de desarrollar una fuerza suficiente para abarcar y retener la multiplicidad concreta del ser sin empobrecerlo ni esquematizarlo. Una reacción indiferente u hostil es siempre una reacción empobrecedora y desintegradora del objeto y significa dejar de lado el objeto en toda su multiplicidad, subestimarlo o superarlo" (Bajtin, 1997:70).

3 "La reflexión epistemológica alerta sobre la ilusión de transparencia de lo real, fija el plano de la ciencia como plano conceptual (que exige el trabajo de y con los conceptos) y, principalmente, revela que el objeto no se deja aprehender fácilmente, toda vez que es regido por una complejidad que se torna opaca y se exige operaciones propiamente intelectuales para su explicación” (Vasallo, 1999:7). 
como la indiferencia o la indignación, dejando al margen otras emociones importantes como el resentimiento, la rabia, la vergüenza, etc. Definido de esta forma, el dilema está en tener o no tener una emoción, es decir, en términos de posesión y autenticidad.

En contraposición, propondremos un modelo que no recurre a la autenticidad de la emoción como criterio valorativo, ni se sirve de dicha autenticidad para justificar, desde el punto de vista político y ético, las acciones y a los sujetos que las realizan. Esta aproximación teórica a la dimensión afectiva en relación a los movimientos sociales se articula en torno a varias cuestiones: la diferencia entre emociones y sentimientos y los mecanismos de interrelación entre ambos; así como, el carácter mediado de lo afectivo y su caracterización como hábito. Para ello, discutiremos algunas de las aportaciones de Antonio Damasio, desde la neurobiología y de Charles Sanders Peirce, desde la semiótica. Además, a partir de la noción de disposición afectiva abordaremos la relación entre creencias (y valores), estilos de vida y estilos emocionales (o estructuras de sentimiento).

Nuestras preguntas de investigación son las siguientes: ¿Cómo intervienen las emociones en la formación de valores y actitudes respecto a la justicia y la injusticia? ¿Es posible defender y promover un repertorio afectivo justo para un espacio público democrático? Escapa a la capacidad de esta investigadora y a los objetivos de esta aportación contestarlas. En estas páginas ensayamos, más que una respuesta tentativa a estas preguntas, una aproximación teórica a un modelo sobre el estudio de las emociones que nos permita elaborarlas de cara a contestarlas en un futuro. La hipótesis de trabajo es que, superadas las dicotomías clásicas emoción-razón, al igual que existe una racionalidad emotiva también es posible defender una emotividad razonable. Consideramos viable investigar acerca de una emotividad justa desde el punto de vista ético, por lo que el desafío específico es saber qué significan las emociones para el área de los estudios sobre comunicación y cambio social, qué repertorio emocional debería guiar sus proyectos e iniciativas y cómo sería posible hacer emerger y reforzar dichos repertorios.

En resumen, el planteamiento surge de una distinción conceptual que puede formularse del siguiente modo: ¿es lo mismo sentir una emoción que estar dispuesto a sentir una emoción?

\section{EL GIRO EMOCIONAL}

En las ciencias sociales contemporáneas se está produciendo una interesante recuperación de las emociones, su incorporación es tan amplia y diversificada que podríamos hablar de un "giro emocional", siguiendo el modelo del "giro lingüístico" de Rorty (1967) y el más reciente "giro cultural". Durante la última década, se ha incrementado el conocimiento interdisciplinar sobre las emociones desde la neuro-biología, la psicología, la sociología, la ciencia política y la filosofía entre otras. El estudio de fenómenos que obligan a mantener una mirada transversal e interdisciplinar, como los fenómenos afectivos, son una oportunidad excelente para trabajar al margen de modas de investigación académica más preocupadas por su 
institucionalización, que por la proyección prospectiva de sus objetos y de la comunidad de interpretación de sus investigadores.

Dentro de este giro emocional, uno de los mayores retos sigue siendo conseguir "conceptualizar las emociones en formas que puedan guiar y sustentar la investigación empírica" (Latorre, 2005:47). Creemos que la semiótica puede ser una herramienta eficaz para ello, por su tradición transdisciplinar y su solvente orientación metodológica. Pretendemos incorporar los aportes de la tradición semiótica al interés contemporáneo por incluir el sentir en el ámbito de análisis social, cultural y político; ya que las emociones se han mostrado como un elemento sugestivo y prometedor a la hora de comprender y explicar la acción colectiva y los movimientos sociales (Latorre, 2005).

En términos generales, cuando hablamos de "giro emocional" no nos referimos a un cambio de paradigma simple o a un nuevo descubrimiento, sino que la incorporación de los afectos en el corpus de conocimiento de las ciencias sociales va acompañada además de la reconstrucción de una historia de olvidos que merece ser analizada. En opinión de Máiz (2011), se produjo una "exclusión fundacional de las emociones en la teoría política moderna", es decir, que el desdeño de la emoción —o para ser más precisos, de cierto tipo de emociones- del campo de la acción política colectiva, reprimió unas conceptualizaciones del sujeto y de la acción en beneficio de otras. La tradición hiperracionalista ha consolidado un modelo hegemónico basado en el del homo economicus y en las teorías de la elección racional, además de una comprensión de la acción colectiva en la que los principios y convicciones morales se sustituyen por criterios normativos más dúctiles y negociables como los intereses. Durante muchos siglos, según explica Máiz, se ha defendido un modelo de privatización e individualización de las emociones que sólo admitía en el espacio público ciertas emociones correctas, las calm passions o pasiones amables — como la admiración—y vetaba las más indómitas y con mayor carga violenta - como la indignación ${ }^{4}$.

El giro emocional, por tanto, se desarrolla en una doble dirección, por un lado, el rastreo de la historia de esta exclusión y, por otro lado, la búsqueda de nuevos instrumentos para reincorporar las emociones al estudio de la acción colectiva en el espacio público. Este segundo ámbito, supone además un reto epistemológico complejo ${ }^{5}$, puesto que "toda consideración sobre la afectividad como objeto analítico conlleva necesariamente un trabajo paralelo y continuado de afinamiento de los instrumentos convencionales heredados de unos paradigmas donde conocimiento, significación e intelección son nociones complementarias" (Surrallés, 2005). Es decir, supone reflexionar sobre la idea de que "el sentir que se siente, el ver que ve, no es pensamiento

\footnotetext{
4 "El concepto de interés, en suma, no sólo implica la expulsión de las pasiones de la esfera de lo político, sino el adelgazamiento de los principios ético-políticos y su reemplazo utilitarista por una enteca idea del Bien, de vida buena, supuestamente compartida por todos los modernos, como maximización racionalista de la utilidad individual" (Máiz, 2010: 20).

5 Este artículo no afronta las dificultades epistemológicas de incorporar la afectividad en la base de los modos de conocer, más allá de que con ello se refuerzan las hipótesis sobre el conocimiento situado de Haraway (1995) y los postulados de las perspectivas postcoloniales que cuestionan los propios modos de conocer en relación a los contextos socio-políticos e históricos específicos, por ejemplo, la noción de desobediencia epistémica de Walter Mignolo (2010).
} 
de ver o sentir, sino visión, sentir experiencia muda de un sentido mudo" (MerleauyPonty citado por Surrellés, 2005). Esto es, aceptar seriamente que si en la base de la racionalidad están los afectos, éstos condicionan la práctica de investigación.

La exclusión de las emociones —o de algunas de ellas - y la falta de análisis de su complejidad, "conduce a un indisimulado hiperracionalismo, que se traduce en la sobrevaloración del consenso y la correlativa elisión del conflicto como dimensión inevitable de la política, desatiende, de la mano de un individualismo racionalista, los procesos de construcción y movilización antagónica de las identidades colectivas; y promueve, por último, el desplazamiento de la política por la moral, el derecho, la economía o la gestión pública (Máiz, 2010:15) ${ }^{6}$. Además, según alerta Peñamarín (2008:64), en términos prácticos esta desatención de las emociones deja el campo libre para que los demagogos actúen activando "emociones colectivizadoras" a través de los discursos públicos, como sucedió por ejemplo durante la Guerra de Irak (Peñamarín, 2009:328); desarmando a "los ilustrados" cuyo único argumento, en muchas ocasiones, consiste sólo en deslegitimar la presencia de las emociones.

Para cuestionar este hiperracionalismo consensual ${ }^{7}$, afrontamos el análisis del universo afectivo en el espacio público colectivo, partiendo de la idea de que los valores y las jerarquías que delimitan lo común y compartido están construidos sobre la proyección afectiva que los sujetos desarrollan en relación al mundo y las normas sociales que lo rigen. De ahí que sostengamos que las disposiciones afectivas son un elemento articulador de la relación democrática e intervienen en las relaciones de justicia e injusticia social ${ }^{8}$. Por esta razón, es pertinente cuestionarse si podemos delimitar una serie de disposiciones afectivas sobre las que proyectar una versión del mundo justa,

6 "En síntesis: la política se ha elaborado teóricamente como el reino por excelencia de lo racional, como la hazaña de la razón. (...) La idea de individuo razonante aislado de los otros, sin vínculos afectivos con los demás conciudadanos; la racionalidad misma reducida a cálculo(...) como maximización del propio interés, sin estar contaminada por afecto, metáfora o esquema interpretativo alguno en el seno de un dispassionate decisión making; el diseño institucional concebido como combinación de mecanismos de agregación e intermediación de intereses, de contrapesos y filtros destinados a 'enfriar' las pasiones, o bien a desactivarlas como calm passions reducibles en última instancia al interés, a fin de que estén lo menos presentes posible en el espacio público...son argumentos varios que han ido elaborándose y entreverándose, si bien de modo diverso y con distinto alcance, desde Descartes a Weber pasando por Kant, de Stuart Mill a la teoría del Rational Choice, Rawls o Habermas" (Máiz,2010: 14).

7 Según Chantal Mouffe (2000), frente a este hiperracionalismo consensual característico la política moderna es necesario otro modelo. La autora propone el modelo agonista que parte de un reconocimiento mutuo entre los contrincantes políticos, para delimitar un espacio de encuentro en el que sea posible el disenso y, por tanto, la política. "The prime task of democratic politics is not to eliminate passions or to relegate them to the private sphere in order to establish a rational consensus in the public sphere. Rather, it is to 'tame' those passions by mobilizing them towards democratic designs. It is necessary to understand that far from jeopardizing democracy, agonistic confrontation is in fact its very condition of possibility" (Mouffe, 2000:149).

8 Compartimos con Ahmed (2004) y con Nussbaum (2012), entre otros autores, las preguntas sobre cuáles son las emociones básicas para la construcción e imaginación del espacio público. Nussbaum se centra en la cuestión de qué emociones deben incorporarse a la deliberación política, mientras que Ahmed piensa en qué hace a una emoción justa. Sigue siendo necesario debatir acerca de qué podría ser una sensibilidad y una razón pública, si cabe hablar de un conjunto de emociones legítimas en el seno de una relación democrática. ¿Es viable realizar una discriminación normativa de los sentimientos democráticos? En realidad, el paradigma de la comunicación y el cambio social es un proceso teórico y de investigación que involucra este tipo de propuestas. El objetivo de estas páginas es llamar la atención sobre la necesidad de tomárselo más en serio y no reducirlo a una concepción revisitada de las calm passions como la solidaridad hegemónica de las últimas décadas. 
y si éstas pueden sostener la imaginación utópica necesaria para la consecución del cambio social perseguido en los modelos de desarrollo alternativo.

Nuestro interés es destacar la doble dimensión de las emociones, su carácter normativo y proyectivo. En este sentido, una disposición afectiva alude a una particular relación de los sujetos con respecto a las normas sociales, pero también apunta hacia elementos emergentes o condiciones de posibilidad. Al afrontar una situación de larga duración de explotación o exclusión se puede generar una disposición que incluye el resentimiento, la rabia, la resignación, etc.; o frente a la desconexión entre las preocupaciones ciudadanas y la gestión política en una coyuntura de crisis se puede estar dispuesto a indignarse o sentir desafección.

Por otro lado, tal y como argumentaremos, la idea de disposición afectiva remite a la posibilidad de acción, esto es, actúa como una guía u orientación para la acción colectiva, lo que presupone la existencia de un espacio de encuentro y contacto entre sujetos, en términos semióticos, de una posición de enunciación colectiva. Si estamos abiertos a sentir un sentimiento - tenemos una disposición afectiva - significa que existe un lugar que puede ser ocupado, una experiencia potencial (que podemos anticipar emocionalmente) $)^{9}$ y que puede transformarse en un acontecimiento o suceso presente; y si nos referimos al espacio público colectivo significa que puedo compartirlo, que me es común a otros (Peñamarín, 2011) ${ }^{10}$. Entonces, según veremos más adelante, la disposición se construye sobre la memoria afectiva compartida en el pasado y se proyecta - gracias al trabajo de la imaginación colectiva - como una memoria de futuro.

Esta doble dinámica, que indica la continuidad de pasado y futuro, de lo establecido y lo porvenir, se combina con una comprensión del universo afectivo construido a partir de niveles de complejidad creciente que se sustentan anidándose unos en otros (Damasio, 2006). Acorde al modelo peirceano, los fenómenos afectivos se categorizan en términos de primeridad, segundidad y terceridad ${ }^{11}$ cumpliendo con los principios de continuidad e interrelación.

\section{EMOCIONES Y COGNICIONES PERCIANAS}

Nuestra concepción general es que las emociones son espacios de mediación semiótica (Saiz, 2009), centrales en la moral, en la ética y en la práctica política

\footnotetext{
9 Más adelante plantearemos la pertinencia del concepto de emociones anticipatorias.

10 "Un paso necesario en el proceso hacia una sociedad del conocimiento dotada de un espacio público democrático será aprender a cuestionar, literalmente, a plantear los asuntos que nos atañen, y en particular las necesidades comunes, como cuestiones, es decir, algo que debe ser tratado y debatido desde diferentes perspectivas y que sólo llegaremos a captar plenamente una vez que hayamos roto los límites de la visión única, consabida, no para abrirnos a un relativismo -del tipo toda visión vale tanto como cualquier otra-, sino a la necesidad de cruzar las perspectivas sobre una cuestión, abrirla a las controversias para valorarla más cabalmente. Un aprendizaje del juego de perspectivas, que pueda facilitar el comprender qué tiene de "racional" cada una de ellas y educar la facultad de ponernos imaginativamente en el lugar de los otros para captar los afectos e intereses implicados" (Peñamarin, 2011).

11 La Primeridad es el modo de ser de aquello que es como es, positivamente y sin referencia a ninguna otra cosa. La Segundidad es el modo de ser de aquello que es como es, con respecto a una segunda cosa pero con independencia de toda tercera. La Terceridad es el modo de ser de aquello que es como es, en la medida en que pone en mutua relación a una segunda cosa con una tercera" (CP 8.328, 1904).
} 
puesto que regulan nuestra vida social y permiten definir los fines y las prioridades de los sujetos. Además, en términos teóricos mantenemos, en primer lugar, que es necesario superar el binomio emoción-razón como realidades confrontadas y excluyentes, puesto que esta dicotomía conlleva nociones de racionalidad excesivamente estrechas (De Sousa, 2012). En segundo lugar, sostenemos que las emociones son fenómenos que involucran manifestaciones corporales en mayor medida que otros estados conscientes. Es decir, la corporalidad forma parte de las emociones; el cuerpo emocionado no interviene sólo en la experiencia psicológica individual sino que es consustancial a los mecanismos de la experiencia social afectiva ${ }^{12}$, a través de fenómenos como, por ejemplo, patrones de gestualidad compartida en la expresión emotiva. Por último, admitimos el sustrato cognitivo de la emoción, lo que no equivale a suscribir una teoría puramente cognitiva de los fenómenos afectivos.

La teoría cognitiva de las emociones es una de las perspectivas de mayor importancia en el giro emocional. En este artículo discutiremos, en particular, una cierta relación entre emoción y creencia, revisamos de qué modo opera esta relación como fundamento del concepto de disposición afectiva, entendida como hábito emocional, un modelo capaz de dar cuenta de la experiencia de las emociones colectivas.

Según Martha Nussbaum (2005:91), la creencia es el "cimiento" de la emoción - su parte constitutiva - y la modificación de las emociones depende de la modificación de la creencia. Sin embargo, las emociones están vinculadas con la cognición no sólo en un sentido unidireccional, de la creencia a la emoción, sino que operan en un doble sentido porque, si bien una creencia puede provocar una emoción, también parece cierto que sentir una emoción y tener una disposición afectiva puede hacer emerger, estimular, crear y reforzar una creencia (Fridja y Mesquita, 2000:45).

Para que sea posible que la emoción genere creencias — contenidos cognitivos- , hay que pensar que lo emocional debe entenderse como fuente generadora de hábitos, esto es un tipo de experiencia que constituye pautas o reglas que guían nuestras acciones y concepciones sobre el mundo, en el marco de una coyuntura socio-histórica determinada y en relación a ciertos objetos y asuntos sociales. Esta concepción "habitualizada" facilita el análisis de lo afectivo en los contextos de mediatización, porque ubica la emoción en el espacio social compartido, la vincula a las creencias y a sus representaciones y, al mismo tiempo, se distancia de un modelo de emoción individualizado que apela a la sinceridad y la autenticidad como criterios explicativos básicos de la experiencia afectiva. Volviendo sobre la hipótesis de la emocionalidad razonable, si las emociones se configuran como fuentes generadoras de hábitos de acción y pensamiento, entonces, "es posible comprender y explicar el que alguien tenga una emoción particular en circunstancias específicas, apelando a razones constituidas por un conjunto de creencias y actitudes particulares que, en todos los otros casos en los que concurran una situación y

\footnotetext{
12 La indagación en este nivel afectivo, esto es, en la experiencia socializada de las emociones y las estructuras de sentimiento cristalizadas en nuestra sociedad, no indica la negación de una dimensión radicalmente individual de la experiencia emotiva, ni tampoco la existencia de aspectos irrepresentables en el campo afectivo, como por ejemplo los abordados por el psicoanálisis como constitutivos de la dinámica inconsciente.
} 
un conjunto de actitudes estructuralmente similares, tenga (racionalmente) que producirse un estado emocional de cierta clase" (Hansberg, 2001:15).

El planteamiento previo se apoya en una lectura de la teoría de las emociones de Peirce a partir del trabajo de David Savan ${ }^{13}$ (1981) y del concepto de estructura de sentimiento de Raymond Williams (1980) ${ }^{14}$. En las páginas siguientes no discutiremos los fundamentos de la teoría peirceana, ya que queremos llevar a cabo una aplicación del modelo como propuesta teórico-metodológica y no una crítica a su obra. Eso supone que obviaremos la explicación de orden metafísico, así como ciertos aspectos conflictivos de la propuesta y nos centraremos sólo en algunos de sus planteamientos ${ }^{15}$. Según Savan, los pilares desde los que reconstruir una teoría de las emociones en Peirce son la tensión entre la duda y la creencia, el principio de continuidad y el agapismo (o teoría del amor creativo).

En términos generales, como predecesor de las teorías cognitivas de la emoción, Peirce sostiene que existe una analogía entre la emoción y el pensamiento, de hecho, describe la emoción como un tipo de cognición. "Toda emoción, toda erupción de pasión, todo ejercicio de voluntad, es como conocimiento" (CP 1.376, 1887). Pero la clave no está tanto en esta analogía sino en la particular teoría peirciana sobre la acción mental. Para él, la operación mental consiste en una sucesión de pensamientos que proceden y se explican en referencia a las reglas de la inferencia válida (Beeson, 2008:290); extrapolándolo, se puede afirmar que la emoción opera siguiendo la lógica de la semiosis y el razonamiento abductivo.

En "Consecuencias de cuatro incapacidades" explica esta analogía de base mediante una evidencia: "En suma, siempre que un hombre siente está pensando en algo. Incluso aquellas pasiones que no tienen ningún objeto definido - como la melancolía - sólo llegan a la consciencia tiñendo los objetos del pensamiento", porque "toda emoción tiene un sujeto. Si alguien está enfadado se está diciendo a sí mismo que esto o aquello es injurioso o vil. Si está alegre, se está diciendo "esto es delicioso". Si se encuentra asombrado se está diciendo "esto es extraño" (CP 5.292, 1868). Por su expresión y pertenencia a un sujeto, se puede inferir que las emociones están dotadas de una exterioridad que permite aprehenderlas mediante un proceso de mímesis o de afectación de un sujeto a otro.

13 Savan menciona las siguientes fuentes para su estudio: "Algunas consecuencias de cuatro incapacidades " (CP 5.264-317, 1868);”La fijación de la creencia” (CP 5.358-387,1877); “Cómo esclarecer nuestras ideas" (CP 5.388-410,1878); "Fundamentos de la validez de las leyes de la lógica" (CP 5.318-357, 1869); "La doctrina de las posibilidades" (CP 2.645-660,1878) y "Amor evolutivo" (CP 6.287-317,1893). A los escritos anteriores se unen "La ley de la mente" (CP 6.102-163) y "Tres tipos de razonamiento" (CP 5.151179). La traducción al español de todos los textos citados en este artículo se encuentran en la página del Grupo de Estudios Peirceanos (http://www.unav.es/gep/).

14 El concepto de estructura de sentimiento ilumina que puede significar el estado latente de una disposición ya que remite a la existencia cultural y compartida de "los significados y valores tal y como son vividos y sentidos activamente (...) Estamos hablando de los elementos característicos de impulso, restricción y tono; elementos específicamente afectivos de la conciencia y las relaciones, y no de sentimiento contra pensamiento, sino de pensamiento tal y como es sentido y sentimiento tal y como es pensado; una conciencia práctica de tipo presente, dentro de una continuidad viviente e interrelacionada" (Williams, 1980:155).

15 Las discusiones sobre la teoría de las emociones en Peirce son todavía escasas. Recomendamos: Savan (1981), Stephens (1981) y Beeson (2008). 
No obstante, las emociones no son igual a otro tipo de cogniciones, son "afecciones de uno mismo más que otras" porque dependen más "de nuestra situación accidental del momento" y, por ello, "son cogniciones demasiado parcas como para ser útiles". Peirce reconoce así la distancia entre las emociones y otras formas de cognición y asevera que "en el caso de una emoción, ésta es una proposición de la que no puede darse razón alguna, sino que está determinada meramente por nuestra constitución emocional"16. Esta afirmación sitúa a la emoción en la órbita de las sensaciones ${ }^{17}$.La emoción se sitúa entre la sensación y el sentimiento lógico, siguiendo la clásica división triádica porque, el hecho de que una emoción dependa más de nuestra constitución emocional, no significa que éstas no sean cogniciones ni que puedan ser equiparadas a los instintos, ya que estos últimos pertenecen al orden de la primeridad (la sensación o reacción primeras, no mediadas). Las emociones son cogniciones porque, para Peirce, toda modificación de la conciencia - atención, comprensión o sensación - es también una inferencia ${ }^{18}$, es decir, todos estos fenómenos participan de los procesos semióticos, lo que les une es que están mediados por signos (Beeson, 2008: 294).

Como dijimos, el esquema peirciano sobre la emoción es, al igual que toda su teoría, triádico. Distingue sensaciones (sentimientos inmediatos) ${ }^{19} \mathrm{o}$ emociones naturales ${ }^{20}$ en la primeridad: emociones sociales o morales ${ }^{21}$ en la segundidad (lo relacional)

16 La cita completa: “Así, una emoción es siempre un simple predicado sustituido mediante una operación de la mente por un predicado altamente complicado. Ahora bien, si consideramos que un predicado muy complejo requiere de explicación por medio de una hipótesis, que esta hipótesis tiene que ser un predicado más simple que sustituya al complejo, y que una hipótesis, estrictamente hablando, es algo difícilmente posible cuando tenemos una emoción, resulta muy patente la analogía de los papeles realizados por la emoción y la hipótesis. Hay, es verdad, esta diferencia entre una emoción y una hipótesis intelectual, que en el caso de esta última tenemos razón para afirmar que con independencia de a qué pueda aplicarse el predicado hipotético simple el predicado complejo es verdad de ello; mientras que, en el caso de una emoción, esta es una proposición de la que no puede darse razón alguna, sino que está determinada meramente por nuestra constitución emocional" (CP 5.292, 1868).

17 Savan (1981) puntualiza que las emociones no son las ocurrencias de los sentimientos inmediatos o sensaciones, porque son recurrentes y están dotadas de cierto grado de identidad y eso sólo puede suceder si están representadas, es decir, si son un signo que existe a través de sus instancias repetidas.

18 "En primer lugar, todo tipo de conciencia entra dentro de la cognición. Las sensaciones, en el sentido en que solamente pueden ser admitidas como una gran rama de los fenómenos mentales, forman una urdimbre y la trama de la cognición, e incluso en el sentido discutible de placer y dolor, son constituyentes de la cognición" (CP 1.381, 1887)

19 En la primeridad, el signo-emoción está corporeizado en el sistema nervioso y en los sentimientos inmediatos de un ser humano. En este sentido, los sentimientos inmediatos (lo que traducido a la propuesta de Damasio serían las emociones de fondo) son las cualidades no cognitivas y no representacionales de las emociones que sirven de base para el espacio semiótico de la emoción (Savan, 1981:323).

20 Las emociones naturales son espontáneas, inmediatas y sin análisis, asociadas a los instintos fundamentales de reproducción y alimentación. Savan (1981:330-331) incluye en esta categoría: la rabia, la repulsión, el miedo, la felicidad al contacto del cuerpo caliente o el dolor frente a la pérdida. Son emociones en las que, en principio, no interviene el aprendizaje ni el acondicionamiento, sino el instinto. Tienen como finalidad la búsqueda de la seguridad, el reposo y el estado de satisfacción no amenazado.

21 Las emociones sociales o morales son emociones reales -en el sentido peirciano- adquiridas a través de la experiencia social (Savan, 1981:331). Están definidas por contraste con respecto a las emociones naturales, porque todas ellas implican la ruptura del estado de calma propio de la primeridad, si bien están conectadas con éstas, porque según el modelo de anidamiento las emociones sociales se desarrollan a partir de la primeridad. De ahí que, en muchos casos, su categorización sea la misma en los dos niveles, como sucede 
y sentimientos lógicos 22 o hábitos - disposiciones afectivas - en la terceridad (lo que implica mediación, convención o hábito). Esta división permite entender el proceso que va desde la sensación como el puro sentir, sin representación ni fundamento cognitivo, hasta la experiencia de la emoción. Peirce describe así este proceso: "una emoción, por otro lado, se incorpora mucho más tarde al desarrollo del pensamiento - quiero decir, mucho después del momento inicial de la cognición de su objeto- y los pensamientos que la determinan ya tienen movimientos correspondientes a los mismos en el cerebro, o en el ganglio principal; consecuentemente, produce amplios movimientos en el cuerpo, e independientemente de su valor representativo, afecta fuertemente al flujo de pensamiento" 23 (CP 5.293, 1868). En resumen, el desarrollo motor de la emoción afecta al pensamiento, incluso si no es una experiencia consciente.

Como abordaremos más adelante, la teoría cognitiva en Peirce afronta la base corporal de las emociones lo que es posible porque, para Peirce, las emociones actúan como interpretantes en un sentido semiótico. "Todo aquello que mínimamente nos interesa crea en nosotros su propia emoción particular, por ligera que ésta pueda ser. Esta emoción es un signo y un predicado de la cosa. Ahora bien, cuando se nos presenta una cosa que se parece a esta cosa brota una emoción similar, de donde, inferimos inmediatamente que la última es como la primera" (CP 5.308, 1868) ${ }^{24}$.

Según leemos en la anterior cita, los objetos-signos pueden establecer relaciones a través de las emociones, esta hipótesis nos conduce hacia la terceridad, el lugar de los sentimientos lógicos o, de otra forma, hacia la fijación de la creencia a través de la emoción. Desde la semiótica peirciana se defiende que tener una creencia equivale a experimentar el "sentimiento de creer" y esto significa haber adquirido un hábito que nos hará estar dispuestos a actuar o interpretar de cierta forma ${ }^{25}$. En el origen de esta creencia está la emoción. Según Peirce, cuando perdemos la certeza

con el miedo o el placer. Pertenecen a esta categoría: cólera e indignación, irritación y resentimiento, afecto y benevolencia, disgusto y desprecio, miedo y culpabilidad, placer y orgullo. Presuponen una norma moral y están guiadas por un interpretante práctico, ya que se adquieren a través de la experiencia y de la participación en relaciones humanas específicas. Así, los pueblos conocen las formas tradicionales tanto por las emociones justas como por las conductas correctas (Savan, 1981:331). Al tratarse de una experiencia real, producida en el marco de las relaciones humanas, estas normas morales y emocionales no están dotadas de carácter universal, sino que están mediadas por un interpretante dinámico, es decir, están forjadas por las fuerzas históricas y componen una memoria que varía de sociedad a sociedad y de época en época. Por esta razón, los objetos de las emociones morales deben ser adquiridos e identificados en cuanto existentes, concretos y actuales, independientemente de su cualidad emotiva.

22 Los sentimientos, según Savan (1981) son sistemas ordenados de emociones, vinculados bien a una persona o una institución, o en el caso de Peirce, a un método como el método científico.

23 Continua la cita: "Los movimientos animales a los que estoy aludiendo son, en primer lugar y obviamente, sonrojarse, parpadear, mirar fijamente, sonreír, fruncir el ceño, hacer pucheros, reír, llorar, sollozar, contonearse, titubear, temblar, quedarse petrificado, suspirar, olfatear, encogerse de hombros, deprimirse, trepidar, henchirse de corazón; etc. A éstos quizá pueda añadirse, en segundo lugar, otras acciones más complicadas, que, en todo caso, surgen de un impulso directo, y no de la deliberación" (CP 5.293, 1868).

24 Este proceso de relación inferencial que puede establecerse mediante una emoción no tiene por qué ser consciente (Beeson, 2008:296).

25 "El sentimiento de creer es una indicación más o menos segura de que se ha establecido en nuestra naturaleza algún hábito que determinará nuestras acciones. La duda nunca tiene tal efecto” (CP 5.371, 1877). "El principio sobre el cual estamos dispuestos a actuar es una creencia” $(C P 1.636,1898)$. 
de una creencia, es decir, cuando nos "asalta" una duda vital o nos vemos obligados a enfrentarnos a lo inconcebible aparece la emoción, que funciona como un motor que impulsa la búsqueda de una nueva creencia. En ese recorrido, la emoción se transforma de primeridad en terceridad - hábito- , es decir, de reacción en disposición afectiva (o en términos de Williams (1980), en estructura de sentimiento).

Recordemos que nuestro objetivo final es apreciar la diferencia entre sentir una emoción y estar dispuesto a sentir dicha emoción. "Esta diferencia resulta esencial para comprender por qué reacciones afectivas socialmente compartidas y sostenidas durante largos periodos de tiempo predisponen a los actores sociales a emprender determinados tipos de acción política" (Rosas, 2011:16).

La noción de disposición nos ayuda en la descripción de las experiencias afectivas compartidas en el largo plazo, especialmente en el modo en que éstas emergen, se refuerzan y evolucionan en los movimientos sociales. Debemos fijarnos en los efectos significativos de las emociones en los movimientos, pero no sólo por su uso estratégico en el marco de la movilización, sino por el lugar que ocupan en sus orígenes y su desarrollo - refuerzo o decadencia. "Podríamos decir que hay emociones que conducen a la participación en un movimiento y otras que se derivan de la actividad en éste (entre otras)" (Latorre, 2005:44). La compasión, la indignación, la rabia o el orgullo pueden articular un movimiento, estar en su origen; de igual mane$\mathrm{ra}$, la experiencia compartida de estas mismas emociones puede transformarse en desesperanza, alegría, entusiasmo o desafección, emociones transformadas que irán acompañadas de nuevos objetos y creencias que han aparecido en el transcurso de la movilización. Según Latorre, "los valedores de las emociones en la investigación de los movimientos sociales destacan que donde realmente facilita e ilumina la investigación es en los momentos de desarrollo de sus actividades, es decir, en la propia sostenibilidad del movimiento" (Latorre, 2005:44). Desde el punto de vista comunicativo, esta reflexión permite ahondar en el modo en que se emplean las emociones estratégicamente para promover un cambio social.

Reiteramos la idea de que para que una emoción compartida pueda sostenerse en el tiempo no puede constituirse como una mera reacción frente a una creencia, sino como una disposición que se proyecta, generando creencias y posibilitando guías de acción. Estas experiencias, características en los movimientos sociales, son fenómenos disposicionales, no reacciones espontáneas ante un suceso, sino tendencias que remiten a un entramado de creencias cognitivas y valoraciones afectivas que construyen y delimitan un objeto frente al que el sujeto se posiciona y que, además, modula un lugar enunciativo compartido con otros. Este abordaje reclama nuevas herramientas teóricometodológicas que expliquen qué significa estar dispuesto a sentir compasión, vergüenza, indignación, culpa, remordimiento, resentimiento o rabia y hacerlo con otros. La descripción de este proceso puede realizarse activando las categorías peircianas.

\section{DE LA EMOCIÓN AL HÁBITO POR LA MEDIACIÓN SEMIÓTICA}

En el campo de la neurobiología, según Antonio Damasio (2006), las reacciones emocionales sirven para regular el proceso vital y promover la supervivencia. La 
regulación del estado vital no persigue la consecución de un estado neutro, como si fuera la ataraxia, sino que busca un estado de bienestar. La emoción es una respuesta química y neuronal que conforma un patrón distintivo, esto es, una disposición para la acción cuyo objetivo es alcanzar dicho bienestar. Aunque los repertorios emocionales están condicionados por la genética, no lo está su activación; de ahí que la emoción no surge de la nada sino que es una respuesta a un estímulo emocionalmente competente (EEC).

A través del concepto de EEC se inserta la instancia de mediación en la conformación de la estructura emocional y, por ello, pueden sostenerse las hipótesis de que la creencia es el sustrato de la emoción y que las emociones son espacios de mediación semiótica. Los EEC son los objetos o acontecimientos cuya presencia real o rememoración mental desencadena la emoción (Damasio, 2005:55). En términos semióticos, los EEC desencadenan procesos interpretativos. Frente al estímulo, el organismo toma una decisión, recomienda evitación y evasión o aprobación y acercamiento, afirma Damasio. Sin embargo, es importante señalar que el procesamiento del estímulo - su valoración - nunca se hace de forma aislada sin memoria, como la de ningún otro signo, sino que se interpreta en relación con otros objetos presentes y en conexión con el pasado, es decir, se realiza activando la memoria y la educación emocional. Por otro lado, este proceso evaluativo no es automático, no hay una unidireccionalidad inmediata entre los objetos causativos y las respuestas emocionales.

Los objetos (en nuestro caso los EEC) no pueden ser concebidos como universales y de comprensión inmediata sino que son socialmente construidos. Los Estímulos Emocionalmente Competentes desencadenan cierta regulación de la emoción, que se conforma estableciendo distancias, relaciones, barreras, intensidades, ritmos, tonos, etc. (La semiótica aporta interesantes herramientas de análisis para estudiar la conformación de la modalidad afectiva a través de las dimensiones de la temporalidad, la aspectualidad, la intensidad, etc.)

El problema está en delimitar qué constituye un EEC, porque como dice Damasio, no existen apenas objetos emocionalmente neutros. La diferenciación emocional entre objetos es una distinción de grados y de orientación positiva o negativa. Precisamente, la capacidad de regulación que atribuimos a las emociones sociales reside en los procesos de construcción de la intensidad o en la conformación de cierta competencia emocional. También en este punto, la semiótica ayuda a analizar los mecanismos a través de los que un signo actúa como EEC, abordar cómo lo emocional se vincula a las representaciones, figuraciones y relatos articulados a través de los discursos en los que se estabilizan las estructuras de sentimiento (Saiz, 2009: 31-49).

Retomando la explicación de Damasio, los seres humanos regulamos nuestro organismo gracias a la producción de emociones "de fondo". Las emociones de fondo son un mecanismo que nos permite tener un mapa que cartografía el estado general del organismo, su tono vital, que puede ir desde el bienestar hasta el malestar. Esta situación de fondo tiene como resultado la configuración de nuestro estado de ánimo, pero además tienen una función reguladora ya que, al contrastar el tono vital con la emoción de fondo, emergen otro tipo de emociones más complejas y sentimientos que modificarán nuestro estado general. 
Como dijimos, las reacciones emocionales persiguen recobrar y mantener un cierto tono vital de bienestar, para conseguirlo, ante un EEC las emociones movilizan repertorios específicos de acción, con los que cartografían nuestro cuerpo - interpretan la emoción de fondo- y producen un cambio temporal de su estado y del estado de las estructuras cerebrales que sostienen el pensamiento - esto es, modifican las creencias. Esta emoción sirve para desplazar el tono vital y así adecuar y preparar de nuevo al organismo a circunstancias propicias para garantizar la supervivencia y el bienestar (Damasio, 2006:56). Para Damasio, las reacciones emocionales dependen de los recursos interpretativos de los sujetos, que son sociales y culturales y se reelaboran continuamente a través de las expresiones y reflexiones humanas, que atañen tanto a la especie como a la experiencia adquirida por cada ser humano.

Retomamos en este punto la descripción del recorrido emocional según la semiótica peirciana, para observar su analogía con los planteamientos descritos por Damasio. Al igual que la triada afectiva peirciana (sensación, emoción y sentimiento), el recorrido afectivo se describe en la obra de Damasio (2006:41) como un proceso de anidamiento que metafóricamente adquiere la figura de un árbol: en la base están las respuestas innatas desde las que se accede a las emociones y los sentimientos, éstos últimos son la expresión mental de todos los demás niveles de regulación homeostática. En ambos casos, el proceso de anidamiento implica que las emociones y reacciones más elaboradas presuponen las más simples e innatas. Como apuntamos más arriba, éstas últimas aunque innatas y estereotipadas, nunca lo son de forma fatal e inevitable, puesto que podemos controlar, en cierta medida, nuestra exposición a los estímulos y su interpretación.

En la obra de Peirce, este anidamiento o división triádica se explica por su principio de continuidad ${ }^{26}$, aunque antes de abordar este complejo principio, ahondaremos en el mecanismo de desarrollo emocional. Nos centraremos básicamente en la terceridad ya que nos interesa destacar el carácter representacional de lo afectivo ${ }^{27}$. La emoción se activa cuando el sujeto abandona un estado de calma y seguridad que le ofrece el hábito de una creencia. El ser humano persigue y, por tanto, prefiere habitar en un estado de calma, de seguridad y creencia antes que en un estado de caos, confusión y duda. En consonancia con las tesis de Damasio, desde el punto de vista peirciano, la creencia es un estado calmo y satisfactorio que no deseamos cambiar o evitar. "El hombre siente que sólo se encontrará plenamente satisfecho si se adhiere sin vacilar a su creencia. Y no puede negarse que una fe firme e inamovible depara una gran paz mental" (CP 5.378, 1877). Por el contrario, "la duda es un estado de inquietud e insatisfacción del que luchamos por liberarnos y pasar a un estado de creencia" (CP 5.373, 1877).La creencia, "tiene justamente tres pro-

\footnotetext{
26 El principio de continuum es el elemento central de la obra de Peirce puesto que sirve para explicar la abducción como mecanismo de afectación de las ideas, principio regulador de la acción mental y de la expansión de la semiosis; la relación cuerpo-mente en la generación de dichas ideas; y la conexión entre las conciencias de los sujetos en el sentir y pensar colectivo.

27 Dejaremos al margen la mención a la primeridad afectiva, esto es, el lugar del sentir como pura posibilidad en cuanto sentimiento lógico que nos acercaría a una perspectiva fenomenológica como la de Merleau-Ponty (Geits, 2002:204).
} 
piedades: primero, es algo de lo que nos percatamos; segundo, apacigua la irritación de la duda, y, tercero, involucra el asentamiento de una regla de acción en nuestra naturaleza, o dicho brevemente, de un hábito" (CP 5.398, 1878). Y lo que el hábito es depende de cuándo y cómo nos mueve a actuar. En resumen, "la irritación de la duda excita la acción del pensamiento, que cesa cuando se alcanza la creencia; de modo que la sola función del pensamiento es la producción de la creencia" (CP 5.394, 1878).

Las emociones son un modo de cognición que surge cuando nuestra mente se enfrenta a circunstancias inciertas, situaciones inconcebibles y complejas que no tienen una respuesta cierta o sencilla ${ }^{28}$.Y estas situaciones de indagación afectiva no se dan a partir de experiencias extraordinarias, como las experiencias científicas de investigación, sino que tienen toda la fuerza de la experiencia vivida y resultan en una creencia viva ${ }^{29}$ (Barrera, 1996:26). Éste es un proceso al que todo sujeto puede enfrentarse y que también está inscrito en los presupuestos sobre el cambio social, porque los proyectos que tratan de hacer frente a situaciones de injusticia reclaman respuestas alternativas, modificaciones del status quo y de las creencias que lo sostienen y, desde el punto de vista ético, algo injusto debería ser percibido como inadmisible.

La fijación de la creencia no es ajena a lo afectivo, no es algo puramente cognitivo puesto que "la terceridad fluye a nosotros por todas las avenidas de los sentidos" (CP 5.157, 1903). Entonces, ¿cómo se alcanza el hábito? La experiencia vivida es el origen de todo proceso de pensamiento. $\mathrm{Y}$ el pensamiento-signo es una idea que, siguiendo la lógica peirciana, se despliega en tres fases: en la primeridad, una idea es puro sentir; en la segundidad, una idea es capaz de afectar a otras $\mathrm{y}$; en la terceridad, la idea puede atraer consigo otras ideas proponiendo un hábito. Según explica en "La ley de la mente", una idea participa del continuum que supone la "idea general"; esta idea general es una instancia que no puede aprehenderse en un instante y que un tiempo finito nunca captará en plenitud. Por eso, la idea en cuanto experimentada tiene que vivirse en el tiempo, en cada intervalo en relación al tiempo general (Geist, 2002: 211). Pero además, la idea tiene una dimensión proyectiva, ya que "una idea general, viva y consciente ahora, es ya determinante de futuros actos, en una medida de la que ahora no es consciente" (CP 6.156, 1892).

Esta dimensión proyectiva explica cómo funciona el procedimiento de significación, de búsqueda de sentido. Los signos crecen y lo hacen por su capacidad de

28 "Las emociones, tal como mostrará una ligera observación, surgen cuando nuestra atención se dirige fuertemente hacia circunstancias complejas e inconcebibles. El miedo surge cuando no podemos predecir nuestro destino; la alegría, en el caso de ciertas sensaciones indescriptibles y peculiarmente complejas. (...) Cuando sucede algo que no puedo explicar, me asombro. Cuando me propongo satisfacer lo que nunca puedo hacer, un futuro placer, espero. "No te entiendo", es la frase de un hombre airado. Lo indescriptible, lo inefable, lo incomprehensible, suscitan habitualmente la emoción” (CP 5.292, 1868).

29 "Para Peirce la experiencia tiene desde un punto de vista metodológico una extraordinaria importancia, ya que el conocimiento se origina siempre en la experiencia. La investigación surge por alguna duda que se nos presenta en nuestra experiencia ordinaria, pero no como el vacuum cartesiano logrado por un esfuerzo de la voluntad, sino como una pregunta definida que la experiencia nos plantea y que necesita ser contestada (...) para Peirce "la experiencia es nuestra única maestra" (Barrena, 1996, 12-13). 
afectación mutua. Al desplegarse en el tiempo el pensamiento crece, las ideas se expanden y se inicia un proceso que Peirce identifica como semiosis ilimitada. En este sentido, la racionalidad peirciana y la emotividad que la acompaña se entienden con referencia al futuro, un futuro posible que alude a la consecución de la armonía y el bienestar.

Según hemos expuesto, las ideas peircianas que iluminan nuestra propuesta se basan en el principio de continuidad, sin embargo no es nuestra intención discutir aquí sus fundamentos (Castañares, 2008). La cuestión derivada del principio de continuidad que nos interesa señalar es, en términos sencillos, que el presente de toda idea "es mitad pasado (vivido) y mitad por venir" (CP 6.126, 1892) y que el vínculo entre ambas instancias se produce a través del hábito. Según Geits (2002), el hábito implica tiempo futuro y narratividad del pasado, porque "el sentir, que no ha emergido aún a la consciencia inmediata, es ya afectable y está ya afectado. De hecho, es hábito, aquello en virtud de lo cual una idea llega a la consciencia presente por medio de un vínculo que había sido ya establecido entre ella y otra idea, mientras estaba aún in futuro" (CP 6. 143, 1892). El mecanismo de formación del hábito es aplicable al ser, al pensamiento, a la representación y, por supuesto, a la emoción. Cuando una emoción alcanza el estado de hábito, se ha transformado en un sentimiento que ordena el pasado y se proyecta en el futuro gracias a su condición de ley. Por ejemplo, las emociones anticipatorias son una de estas formas de proyección, consisten en "un pronóstico, predicción o imaginación de emociones reales que pueden tener lugar bajo ciertas condiciones particulares" (Rosas, 2011:17). Es decir, desde el presente podemos imaginar la alegría futura si ganáramos una batalla, o nuestra posible desesperanza si fracasáramos. Más adelante retomaremos esta cuestión para referirnos al impacto de las emociones anticipatorias sobre la acción.

Es importante destacar que el hábito nunca se resuelve en el espacio individual sino que se fortalece por la participación de la comunidad. De ahí que la idea de hábito sea central para articular una reflexión sobre las emociones colectivas. Siguiendo con el principio de continuidad, escribe Peirce en "La fijación de la creencia":

Esta concepción de que el pensamiento o el sentimiento de otro hombre pueda ser equivalente al de uno mismo constituye claramente un nuevo paso, y de gran importancia. Surge de un impulso demasiado arraigado en el hombre como para suprimirlo sin poner en peligro la destrucción de la especie humana. A menos que nos transformemos en eremitas, nos influimos necesariamente en las opiniones unos a otros; de manera que el problema se transforma en cómo fijar la creencia, no meramente en el individuo, sino en la comunidad (Peirce, CP 5.378, 1877).

Aplicando la idea de hábito, el recorrido de una emoción sería el siguiente: los sujetos desean y persiguen estados de paz, de calma en la creencia y su perturbación sucede con la aparición del conflicto. En esta situación, la duda es una experiencia intrusiva y disruptiva, que provoca la ruptura de los modos de comportamiento ordinarios y de las emociones previas que se habían configurado como un hábito (Savan, 1981:327). Esta turbulencia, que reclama toda la atención y la energía del sujeto tanto mental, como afectiva y corporal, es imperativa en su dinámica. La búsqueda del sentido, el avance de las ideas y la conclusión en la fijación de las creencias fun- 
cionarán gracias a la emoción agápica, esto es, a la afectación de unas ideas sobre otras que se atraerán hasta confirmarse como pautas, reglas y modos de actuación compartidos por una comunidad y que orientarán sus pensamientos, sus emociones y sus acciones futuras. Como avanzamos, el sentimiento de creer en algo es indicativo de que hemos alcanzado un hábito, se ha fijado una creencia que orientará nuestras acciones. Eso no significa una determinación inamovible, ya que "la creencia no nos hace actuar automáticamente, sino que nos sitúa en condiciones de actuar de determinada manera, dada cierta ocasión" (Peirce, CP 5.376, 1877).

Más arriba, siguiendo la teoría cognitiva clásica, recordamos que las emociones son parte de nuestras creencias o, lo que es lo mismo, que una creencia lleva implícita una valoración afectiva - y axiológica - del objeto de dicha creencia. Ahora, a través de la idea del hábito peirciano, lo que queremos destacar es la relación inversa: cómo las emociones al "habitualizarse", estabilizarse como reglas de interpretación y convertirse en sentimientos, afectan a las creencias, bien haciéndolas emerger cuando no existen o bien estimulándolas, reforzando o modificando las existentes. Generalmente, "cuando pensamientos normalmente causativos de emociones aparecen en la mente, producen emociones, las cuales dan origen a sentimientos, y éstos evocan otros pensamientos temáticamente relacionados y que es probable que amplifiquen el estado emocional" (Damasio, 2006:72).

Estos procesos de semiosis, en otros términos, de interpretación que originan crecimiento o afectación, no funcionan de manera lineal en una sola dirección, sino como mecanismos intertextuales de naturaleza inferencial — creativa — que amplían, hacen crecer, las redes entre pensamientos, sentimientos y emociones. Pese a la dimensión creativa y amplificadora del sentimiento eso no significa que estemos ante un proceso de plena libertad, puesto que la disposición siempre presupone una cierta orientación. Por eso, la emoción produce el tipo de pensamientos adecuados a la disposición afectiva concordante, tal y como afirma Peirce, esto sucede porque una idea está siempre in futuro por su afectación con otra. Desde otro punto de vista, "ello es debido a que el aprendizaje asociativo ha conectado las emociones con los pensamientos en una rica red de dos direcciones. Determinados pensamientos evocan determinadas emociones, y viceversa. Los niveles cognitivos y emocionales de procesamiento están continuamente conectados de esta manera" (Damasio, 2006:73). Esto significa que los pensamientos y las emociones de los sujetos establecen relaciones de sentido con otros objetos (pensamientos o estados emocionales) que funcionan como sus interpretantes. Y esta cadena de interpretantes, de naturaleza creativa, hace crecer el signo de origen y, por ello, "los pensamientos evocados pueden funcionar incluso como disparadores independientes de emociones adicionales y así potenciar el estado afectivo en curso" (Damasio, 2006:72).

\section{RELACIÓN ENTRE EMOCIÓN Y DISPOSICIÓN AFECTIVA}

Utilizando las ideas peircianas - aunque sin mencionarlas - en el campo de la psicología, Fridja y Mesquita (2000) aplican estos planteamientos y proponen la diferencia entre una emoción como ocurrencia y un sentimiento o disposición afectiva como estado latente. 
Si aceptamos la distancia entre emoción como reacción y sentimiento como hábito, podemos entender las disposiciones afectivas como procesos temporales dilatados que producen nuevas formas de semiosis en los planos afectivo y cognitivo. En este sentido, una determinada experiencia emocional puede dar lugar a una creencia que tenga como función gestionar, justificar, dar sentido a dicha emoción. Por ejemplo, actualmente la sociedad mediatizada y globalizada nos impide ser ciegos a determinadas situaciones de injusticia; éstas pueden obviarse, negarse, pero no es factible - en la mayoría de los casos - eludir su conocimiento por mínimo que éste sea. Esta percepción puede provocar en los sujetos experiencias afectivas de muy diverso signo, entre ellas, cierta sensación de culpabilidad derivada de una conciencia difusa de la responsabilidad ante dicha injusticia. Esta experiencia afectiva puede estar en el origen de la emergencia de un conjunto de creencias que sirvan para dar sentido a este marco emocional y justificar la valoración afectiva del objeto que lo ha provocado (delimitación de una injusticia). En este caso, los sujetos pueden buscar razones para odiar o menospreciar a aquellos a quienes se ha herido o humillado - las víctimas de esa injusticia - (Fridja y Mesquita, 2000: 52-54) o bien, elaborar creencias sobre la inevitabilidad del contexto, la falta de responsabilidad propia, etc. Estas creencias a su vez pueden derivar en otras emociones, nuevas creencias o formas de acción que tomarán una u otra dirección en función de la disposición afectiva que los sujetos activen en relación a este asunto o situación. Lo que tratamos de explicar es que se puede compartir la emoción de culpabilidad - de hecho, creemos que es parte de nuestra posición como sujetos morales hoy_-, pero el desarrollo de ésta dependerá de la disposición afectiva, los pensamientos y creencias que la interpreten. Evidentemente, no es lo mismo tener una disposición indignada frente a la injusticia, que compasiva o indiferente. Por supuesto, estas disposiciones así descritas son tipos ideales que actuarán en términos polifónicos, hibridándose en su articulación concreta.

Si la función del sentimiento como hábito es ampliar los límites de la reacción emotiva y proyectarla en el futuro, para que esto suceda deben cumplirse ciertas condiciones: tiene que darse una emoción particular en relación a un objeto, con una duración prolongada y que indique una tendencia o disposición para interpretar o actuar referida a dicho objeto. A la luz de estas características, los sentimientos pueden caracterizarse según Fridja y Mesquita de dos modos: (1) como disposiciones para responder emocionalmente a un objeto dado; (2) como esquemas afectivos compuestos de una representación latente de un objeto relevante para nuestras preocupaciones, que sugiere qué tipo de acción sería deseable (Rosas, 2011: 16). En resumen, una respuesta emocional y una representación orientada a la acción.

La definición de sentimiento de Damasio también incluye estos dos componentes. Para este autor, el sentimiento es "la percepción de un determinado estado del cuerpo junto con la percepción de un determinado modo de pensar y de pensamientos con determinados temas" (Damasio, 2006:86). Son acontecimientos mentales significativos que llaman la atención hacia las respuestas emocionales que los generaron, y hacia los objetos o EEC que desencadenaron dichas emociones (Damasio, 2006: 172).

Los sentimientos no sólo llaman la atención hacia estos dos fenómenos sino que conducen al sujeto a creer en la verdad, tanto de sus experiencias emocionales como 
de los juicios asociados a éstas; actúan como una especie de condición de verosimilitud o plausibilidad. Fridja y Mesquita (2000: 54-55) explican que las creencias que forman parte de los sentimientos involucran generalizaciones (leyes), esto es, se refieren a las propiedades estables e intrínsecas de los objetos o a lo que éstos pueden producir. Estas creencias, incluso si son pasajeras, al remitir a elementos estables del objeto son creencias sobre aspectos y fenómenos que se consideran persistentes y son pensamientos que se mantienen en el tiempo. Y, por último, durante el tiempo que perduran son creencias arraigadas, dotadas de un alto grado de verosimilitud como certezas subjetivas.

Ante una decisión política particular en la situación de crisis podemos tener una reacción emocional desesperanzada. Durante el tiempo que dure este "ataque" de desesperanza, puede que nos convenzamos de que la acción colectiva no sirve, pensemos que todo es un sinsentido y nos invada el nihilismo; creeremos firmemente en estas ideas y las generalizaremos. Además, tanto la tendencia afectiva - desesperanza - como las creencias derivadas - nihilistas - pueden verse fortalecidas por el entorno colectivo. Para producir un cambio, no se requiere únicamente que cambie la creencia sobre el sinsentido de la lucha o que ésta desaparezca; también puede producirse un cambio social si existe una disposición afectiva más consolidada con la que esta reacción se complementa. Imaginemos que hay una disposición afectiva "indignada" que sostiene la creencia en la necesidad y el poder de la acción colectiva y que rechaza la resignación como parte de su repertorio afectivo; la activación de esta disposición modificará, atenuará, con el paso del tiempo, la viveza de la desesperanza, puede que incluso la haga desaparecer. Sin embargo, en el tiempo que la reacción desesperanzada persistió, las creencias fueron ciertas para nosotros.

Con respecto a la veracidad y credibilidad de emociones y creencias, hay que atender a la diferencia entre el proceso de valoración que caracteriza a una emoción y la creencia generada a partir de ella. "La pregunta apunta a saber si la creencia generada a partir de una emoción es una simple extensión de la valoración original, en cuyo caso sentimiento y emoción constituirían una y la misma experiencia afectiva" (Rosas, 2011:17). La respuesta es negativa, aunque puedan parecer instancias iguales, no se solapan y no pueden ser asimiladas. Es distinto valorar un objeto que determinar la validez de una creencia o verificar un juicio, es decir, una cosa es valorar un objeto como peligroso y sentir miedo ante ello y otra que la creencia que ha provocado dicho miedo sea falsa o verdadera. Esta distinción es clave para argumentar la diferencia entre emociones y disposiciones, ya que aunque valoración y creencia son dos instancias evaluativas de tipo cognitivo, "los niveles epistemológicos en los que ellas se sitúan difieren entre sí", afirma Rosas y sugiere la lógica triádica peirciana.

Por otra parte, valoración y creencia funcionan de modo distinto en las emociones y en los sentimientos. Veamos algunos ejemplos. En un primer caso, el gobierno anuncia una batería inespecífica de recortes que afectarán al trabajo en la universidad, ese discurso poco elaborado me lleva a pensar que perderé mi empleo y siento miedo ante lo que sucederá. En un segundo caso, la desafección frente a la acción colectiva me hace creer que las reivindicaciones conjuntas son ineficaces e incluso peligrosas para mis intereses y eso me dispone a actuar en mi entorno laboral de modo individualista. 
Rosas plantea que, una vez que un sujeto ha percibido e identificado un objeto, la valoración afectiva que haga de dicho objeto será verdadera para él, incluso si dicha valoración está basada en una creencia falsa. Es decir, aunque a posteriori se demuestre que las pretensiones del gobierno no afectan a mi puesto de trabajo, la valoración afectiva que provocó mi reacción miedosa no se anula, ni deja de existir y nuestro miedo es verdadero. La valoración afectiva de los recortes cumplió su objetivo, orientó nuestras acciones poniéndonos en posición de alerta.

Por su parte, "las creencias generadas por las emociones y fijadas en disposiciones afectivas (también) tienen criterios empíricos de verificación que nos permiten afirmar su verdad o falsedad" (Rosas, 2011:18), sin embargo las consecuencias de esta verificación son diferentes. En el segundo caso que hemos propuesto, una nueva situación puede demostrarnos que la creencia en la ineficacia de la acción colectiva es falsa, por ejemplo, un grupo de compañeros se alía para evitar despidos en el centro de trabajo. Si confirmamos la falsedad de nuestra creencia, esta verificación $a$ posteriori puede provocar la modificación y anulación de la disposición afectiva que la acompaña, es decir, desplazar la desafección frente a las luchas colectivas hacia otra disposición más favorable a éstas. En resumen, si la creencia que acompañó al afecto se demuestra falsa cambiarán las condiciones de la disposición: pueden anularse, bloquearse, mermar o incrementar su intensidad, etc. No obstante, esto también puede suceder por otros motivos, por ejemplo, si se produce una nueva valoración de la reacción emocional, esto es, si llegamos a la conclusión de que nuestra primera emoción fue inadecuada, inoportuna, exagerada, etc ${ }^{30}$.

Lo que esto demuestra es que entre las emociones y las disposiciones afectivas se produce un salto cualitativo, la última no es mera prolongación de la primera, no hay un paso de la primeridad a la terceridad como un recorrido lineal; sino que, tal y como explicamos, las emociones crecen y se transforman en hábitos a través de la semiosis. Este proceso implica otra característica en la transformación: la primera valoración afectiva del objeto que desata la reacción emocional no permanece estable a lo largo del proceso de configuración de la creencia y consolidación de la disposición, puesto que todo proceso de semiosis o búsqueda de sentido es un proceso creativo (Castañares, 2008). No sólo la valoración emocional, sino la propia naturaleza y características del objeto se van desplazando y modificando en el hacer performativo de la disposición afectiva. En otra palabras, la creencia sobre el objeto, la fortificación del hábito, no es un puro hacer cognitivo desde lo representacional, sino que involucra a la disposición.

Para ilustrar esta condición podemos observar como funcionan ciertos procesos psicológicos, como la "rumiación". Cuando tiene lugar un proceso de rumiación lo que sucede es que la actividad cognitiva desplegada a partir de la emoción amplía los límites de dicha reacción emocional, esto es, aumenta o disminuye la intensidad

\footnotetext{
30 Por ejemplo, el entusiasmo que sentimos frente a la acción colectiva nos invita a creer en el poder de ésta y nos dispone a apoyarla y actuar a favor de su promoción. Como sentir es una cuestión de tiempo, una experiencia emocional dilatada se puede revisar, en este ejemplo podríamos constatar que nuestro entusiasmo en el apoyo a los proyectos colectivos es desmedido y promueve creencias falsas, poco realistas o excesivamente optimistas.
} 
afectiva en función de las creencias, valoraciones y justificaciones sobre el objeto que se desencadenaron a partir del primer estadio de la emoción (Frijda y Mesquita, 2000:54). Este lapso temporal, en el que actúan interrelacionadas creencias y emociones, sirve para explicar fenómenos como la polarización de los conflictos.

En uno de los ejemplos previos, vimos que la percepción de una situación de injusticia puede provocar incomodidad en el sentido emocional; en la búsqueda de sentido a esa emoción, activamos prejuicios sobre las víctimas que, sin embargo, no sirven para apaciguar la emoción incómoda ya que no logran cubrir el espacio de disonancia cognitiva - no es fácil acusar a una víctima de su propia situación. El sostenimiento de la emoción corre en paralelo con la elaboración de creencias que persiguen alcanzar una justificación satisfactoria. Lo importante en el mecanismo de rumiación es que la disposición afectiva hará que aceptemos — aunque sea de modo temporal - las creencias activadas. Por ejemplo, Frijda y Mesquita (2000:54) explican que cuando sentimos vergüenza, el miedo al rechazo y el sentido del ridículo que experimentamos provocan un cierto grado de acuerdo con la posición de una audiencia - tal vez presupuesta - que se mofa o nos desaprueba.

Extrapolando el mecanismo de rumiación, sostenemos que la elaboración de las creencias tomará una y otra deriva en función de la disposición afectiva que oriente la reacción emocional. Y, en sentido inverso, la prolongación y reiteración de la experiencia afectiva, así como de las creencias asociadas contribuirán a la fortificación y fijación de la disposición afectiva.

\section{PROPUESTAS PARA EL CUIDADO ${ }^{31}$ DE ESTAS IDEAS}

En los apartados anteriores hemos tratado de demostrar teóricamente a partir de la obra de Peirce que la fijación de una creencia derivada de un proceso emocional genera una disposición a sentir, pensar y actuar de cierta forma, siempre que se active un proceso (o EEC) cuya naturaleza y características como signo quedan definidas en el marco de su estructura de sentimientos de referencia. En otras palabras, las emociones se convierten en hábitos, trasformadas en sentimientos y operan como disposiciones, es decir, las emociones no son un fenómeno reactivo, sino que cumplen la condición de ley, una regularidad dotada además de una dimensión proyectiva y, por ello, pueden actuar como motivaciones y razones para orientar y promover la acción colectiva.

Para terminar este artículo nos gustaría mencionar, a modo de apuntes, tres posibles vías para el cuidado (investigación) de estas ideas. En primer lugar, la importancia de las emociones anticipatorias en la configuración del hábito y la orientación

31 El cuidado de las ideas es una propuesta peirciana, basada en el ágape como motor del conocimiento. Peirce lo explica de la siguiente forma: "Supón, por ejemplo, que tengo una idea que me interesa. Es mi creación. Es mi criatura; (...) es una pequeña persona. La quiero; y moriría por perfeccionarla. No es aplicando la fría justicia al círculo de mis ideas como las haré crecer, sino queriéndolas y cuidándolas como lo haría con las flores de mi jardín" (CP 6.289, 1893). También nos recuerda que estas ideas que cuidamos y queremos no aparecen en el vacío, porque siempre pensamos desde otros y con otros. 
de la acción; en segundo lugar, la dimensión figurativa — representacional— de las disposiciones y en tercer lugar, su análisis como mecanismo enunciacional y sus implicaciones éticas.

\subsection{EMOCIONES ANTICIPATORIAS}

Las disposiciones afectivas incluyen emociones anticipatorias y una anticipación emocional es, como expusimos más arriba, un pronóstico, predicción o imaginación de emociones reales que pueden tener lugar bajo ciertas condiciones particulares" (Rosas, 2011:17). Fridja (2007:44-45) las incluye en la categoría de inner o small emotions puesto que son emociones de baja intensidad que funcionan casi como una intuición, su efecto en términos de reacciones motoras es pequeño, pero no así sus posibles consecuencias que pueden ser muy potentes. Las emociones anticipatorias son una de las categorías que más afecta a la acción de los sujetos. Según Fridja, están en la base de experiencias como: afiliarse a un partido político, dar dinero a una causa o esconder a una persona perseguida. Son una especie de intuición emocional que nos permite que emerja una idea con claridad, porque la naturaleza de una idea se adivina, intuye, antes de que la mente la posea (CP 6.307, 1893) y, a partir de ahí, es posible que genere creencias duraderas en el marco de la disposición afectiva.

Desde el punto de vista peirciano, se explican por la capacidad de las ideas de estar in futuro, porque "una idea general, viva y consciente ahora, es ya determinante de futuros actos, en una medida de la que ahora no es consciente" (CP 6.156, 1892) y por el proceso creativo de la abducción. Es importante señalar que estas emociones anticipatorias no son cogniciones en un sentido proposicional, sino que se articulan como representaciones, imágenes de esquemas de tendencias que podrían suceder (Fridja, 2007). Las podemos interpretar como figuraciones que no sólo orientan la acción futura, sino que repercuten fundamentalmente sobre nuestros modos de acción actuales. Para Fridja (2004), muchas de las emociones sociales como la vergüenza, la culpabilidad o los celos funcionan sobre la base de las emociones anticipatorias. Actuamos con prudencia y humildad porque anticipamos los posibles sentimientos de culpa o para evitar la vergüenza. Es decir, el curso de nuestra acción está marcado por los relatos sobre las experiencias emocionales que pueden producirse en un futuro y que podríamos llegar a sentir si se cumplen las expectativas de interpretación sobre la situación que estamos valorando. La anticipación de este relato emocional puede provocar un cambio en el curso de la acción. Estas inferencias previstas en la interpretación son posibles por la existencia de un hábito

Por ejemplo, el movimiento indignado se ha mantenido y prolongado, entre otros aspectos, por la anticipación del sentimiento de alegría frente a la posibilidad de producir un cambio socio-político desde la acción colectiva. "Esta anticipación emocional generará y fijará creencias referidas a un nuevo orden social, creencias que los dispondrán a pensar y actuar de acuerdo con la pertinencia de su objeto intencional" (Rosas, 2011: 17). Esta anticipación de la alegría por el cambio no sustituye a la alegría presente, como ocurrencia, por el placer de compartir con otros un sueño (verse afectado por otros en la creencia y la emoción). Esta alegría presente 
se puede experimentar con intensidades diversas en el marco de las manifestaciones, por ejemplo, en función de que se comparta, en mayor o menor grado, una posible disposición afectiva alegre u optimista construida sobre el entusiasmo y la fe en la capacidad de la acción colectiva.

Las emociones como fenómenos que están por venir y cuya función es buscar respuesta a lo inconcebible, a lo "dudoso", no sólo rigen nuestra acción actual - cumpliendo una función normativa - sino que, al mismo tiempo, abren horizontes de posibilidad. En su proyección hacia el futuro, la experiencia de una emoción "habitualizada" (instituida como regla) puede desplazarse y crecer, puede activar recorridos o relatos emocionales conocidos o instigar la emergencia de otros nuevos.

\subsection{ORDEN REPRESENTACIONAL DE LA DISPOSICIÓN}

Hemos dicho que las creencias temporales derivadas de las emociones tienden a reforzarse y fijarse en estructuras de sentimiento más complejas que se traducen en la estabilización de representaciones compartidas, así como procesos de justificación y argumentación que sirven para dar sentido a las experiencias emocionales. Defendemos, por tanto, que si existe una disposición afectiva debe existir también una estructura de sentimientos organizada sobre un conjunto de figuraciones comunes $^{32}$ (Saiz, 2009: 58-67).

Cuando nos encontramos con una estructura de sentimiento, significa que las emociones se sostienen sobre una serie de creencias y valores que forman un horizonte de sentido compartido a través de representaciones y narraciones. Y todo este entramado es el que promueve una disposición afectiva que guiará los procesos de interpretación posteriores y facilitará las acciones colectivas conjuntas. Por tanto, necesitaremos analizar estas lógicas representacionales que afectan a la definición de los imaginarios compartidos - y que conforman además las narrativas personales- para conocer en qué consiste y cómo se articula una disposición afectiva ${ }^{33}$.

Esta mirada nos acerca, entre otros, al análisis de las emociones narrativas ${ }^{34}$, puesto que los relatos, delimitados culturalmente, contienen y nos enseñan formas de sentir y de vivir, "los relatos construyen en primer lugar y después invocan (y refuerzan) la experiencia del sentir" (Nussbaum, 2005:526). Son la fuente principal de la vida emocional de cualquier cultura, por lo que si los sujetos hemos aprendido

\footnotetext{
32 Comprendemos las figuraciones como instancias de mediación, esto es, las composiciones individuales y colectivas que habitamos y en relación a las que proyectamos nuestras expectativas vitales. Las figuraciones constituyen arquitecturas enunciacionales que muestran la disyunción y distancia existente entre los diversos actores; fundamentalmente, entre los sujetos de los enunciados y el sujeto de la enunciación, así como, entre los actores delegados de la propia enunciación, aquellos a través de los que ésta se despliega y encarna en un discurso (Saiz Echezarreta, 2008: 80).

33 "Se trata de descubrir las circunstancias reales en que (las emociones) puedan ser un árbitro y utilizar el acoplamiento razonado de circunstancias y sentimientos como guía para el comportamiento humano" (Damasio, 2005:173).

34 Las emociones narrativas están modeladas no sólo por formas de cognición lingüística, según Nussbaum (2005), sino que en ellas también intervienen narraciones musicales o pictóricas.
} 
un tipo de repertorio emocional o afectivo, podemos llegar a desaprenderlo, esto es, desarrollar una labor deconstructiva del universo pasional, labor propia de la educación sentimental. La crítica a una determinada emoción o a un repertorio efectivo consistirá en la deconstrucción de los relatos que la configuran y vehiculan, de aquellas tramas sustantivas y géneros instituidos como paradigmáticos. En el campo de la comunicación y el cambio social, por ejemplo, tan importante es proponer emociones como desmontarlas.

La existencia de emociones narrativas presupone que, en el marco de una disposición afectiva, un cierto tipo de relato va a mostrar o representar una emoción pero, de igual forma, la emoción misma va a suponer la aceptación, el consentimiento de vivir conforme a un cierto tipo de relato (Nussbaum, 2005:516). Una disposición afectiva - compasión, ira o resentimiento - se corresponde con relatos muy diferentes sobre las relaciones nosotros-ellos en el espacio de los conflictos. En resumen, activar una disposición significa, principalmente, aceptar un cierto tipo de relato. Conforme a lo anterior, nuestros intereses teóricos y metodológicos persiguen poder hablar de los discursos que posibilitan las disposiciones afectivas, no sólo como espacios de representación de las emociones, sino como máquinas capaces de movilizarlas y generarlas.

\subsection{ESPACIO ENUNCIACIONAL}

"Toda cognición implica algo representado, o aquello de lo que somos conscientes, y alguna acción o pasión del yo mediante la cual llega a ser representado" (CP 5.238, 1868). Entendemos, pues, que para Peirce, en toda cognición y, por tanto, en todo proceso afectivo está implicado lo enunciado y su enunciación. Más aún, la conciencia que nos permite mantener nuestra vida en común es la síntesis que capta el instante de una cognición y su proceso (CP 1.381, 1887) ${ }^{35}$.

La semiótica ha demostrado que la enunciación es siempre una instancia apasionada, aunque varíen sus grados de intensidad; así mismo, el lugar enunciativo puede definirse como encuentro de conciencias, un espacio polifónico (Bajtin, 1997). Más allá de admitir que el soporte social fortifica la creencia (Rosas, 2011), el estudio de la dimensión enunciacional de las disposiciones afectivas nos permitirá corroborar si estar dispuesto a sentir una emoción equivale a reconocer un espacio enunciativo compartido, un lugar de encuentro en el que sentir con otros, participar de la emoción y enfrentarnos al conflicto que eso supone. Si eso fuese cierto, estar dispuesto a sentir de un modo justo implicaría estar dispuesto a establecer un

\footnotetext{
35 "Ese elemento de la cognición, que no es ni sensación ni sentido polar, es la conciencia de un proceso y esto en la forma de un sentido de aprendizaje, de adquisición, de crecimiento mental es eminentemente característico de la cognición. Este es un tipo de conciencia que no puede ser inmediato, porque cubre un tiempo, y eso no meramente porque continúa a través de cada instante de ese tiempo, sino porque no puede ser contraído a un instante. Difiere de la conciencia inmediata como una melodía difiere de una nota prolongada. Ni siquiera puede la conciencia de los dos lados de un instante, de una "ocurrencia" repentina, en su realidad individual, posiblemente abarcar la conciencia de un proceso. Esa es la conciencia que ata nuestra vida. Es la conciencia de síntesis" (CP 1.381, 1887).
} 
diálogo ético, es decir, admitir la existencia de una zona de contacto emocional (Ahmed, 2004:194).

En el espacio público y en relación al cambio social, lo anterior no significa participar de las calm passions, habitar un territorio afectivo cómodo y armónico; sino, por el contrario, sentir de modo justo es aceptar lo agonístico (Mouffe, 2000). Según Maturana, si este encuentro es agresivo no habrá lugar para la compresión mutua, debe haber intención de encontrarse y aceptar el contacto para que pueda pasar algo en común. Es la disposición a un "sentir justo" la que genera el espacio de encuentro y no al revés. Y entre otros fenómenos que pueden suceder en la zona de contacto, estar dispuesto a sentir con otros es estarlo a experimentar los límites del sentir y las fronteras de la relación ética (Saiz, 2007). El espacio público democrático puede articularse sobre el sentimiento de solidaridad o el de compasión pero, incluso suponiendo que hay intención de encontrarse: ¿hay lugar para dialogar con la rabia o el resentimiento?

En conclusión, una disposición afectiva implica una forma de estar en el mundo $y$, cuando es compartida, crea elementos de enunciación colectiva; genera figuraciones (representaciones, lexicalizaciones, tonos e intensidades, etc.) estabilizadas en imaginarios compartidos; participa de la construcción de identidad a través de la delimitación de un objeto intencional; genera fronteras y conflictos en la construcción de dicho objeto y produce el disenso imprescindible para la acción colectiva en la esfera pública, porque al emocionarnos estamos afrontando lo inconcebible y cuestionándonos el estatus quo (la fijación de la creencia).

El modelo sobre las disposiciones afectivas que hemos intentando articular nos ayuda a no eludir cuestiones como la compleja relación entre emoción, violencia y poder, o afrontar el lugar central de las emociones en la política. Nos permite situar nuestro interés analítico en los sentidos potenciales, en aquello que está aún por imaginar; una mirada que la investigación sobre cambio social comparte con los movimientos sociales. En ambos casos, se persigue la transformación hacia el ideal de justicia y equidad que se despliega gracias a la acción del ágape. 


\section{REFERENCIAS BIBLIOGRÁFICAS}

AhMED, Sarah (2004): The cultural politics of emotion. Edinburgh: Edinburgh University Press.

BARRENA, Sara (2007): La razón creativa. Crecimiento y finalidad del ser humano según C. S. Peirce. Madrid: Rialp.

Barrena, Sara (1996): Introducción a Charles S. Peirce. Un argumento olvidado a favor de la Realidad de De Dios. Cuadernos de Anuario Filosófico.

BEESON, Robert (2008): "Peirce on the passions: The role of instinct, emotion and sentiment in inquiry and action". Theses and dissertations. Paper 134 University of South Florida

CASTAÑARES, Wenceslao (2008): "El acto creativo: Continuidad, innovación y creación de hábitos". Utopía y Praxis Latinoamericana, 13, 40: 67-81.

Damasio, Antonio (2005): En busca de Spinoza. Neurobiología de la emoción y los sentimientos. Barcelona: Crítica.

(2006): El error de Descartes. Barcelona: Crítica.

DE SousA, Ronald (2012): "Emotion". The Stanford Encyclopedia of Philosophy. Edward N. Zalta (Ed.) [ http://plato.stanford.edu/archives/spr2012/entries/emotion/]

FriJdA, N. \& Mesquita, B. (2000): "Beliefs through Emotions" en Frijda, N et al (Eds.) Emotions and Beliefs. How Feelings Influence Thoughts. Cambridge: Cambridge University Press. 45-77.

FrIJDA, Nico H. (2004): "Emotion and action" en Feelings and emotions. (Eds) Manstead, A. et al. Cambrigde: Cambridge University Press. (2007): The laws of emotion. New Yersey: Routledge.

GEIST, Ingrid (2002): “Juego, estado del sentir y experiencia en el ritual”. Escritos, Revista del Centro de Ciencias del Lenguaje. 26: 183-225

HANSBERG, Olbeth (2001): “Las emociones y la explicación de la acción”. Isegoría, 25:.5-17.

HARAWAY, Donna (1995): Ciencia, cyborgs y mujeres: la reinvención de la naturaleza. Madrid: Ediciones Cátedra.

LAtORRe CATAlán, Marta (2005): “Los movimientos sociales más allá del giro cultural: apuntes sobre la recuperación de las emociones". Política y sociedad, 42-2: 37-48.

Máız, Ramón (2010): "La hazaña de la razón: la exclusión fundacional de las emociones en la teoría política moderna". Revista de estudios políticos, 149: 11-45.

Maturana, Humberto (2001): Emociones y lenguaje en educación y política. Santiago de Chile: Dolmen Ediciones.

Mignolo, Walter (2010): Desobediencia Epistémica. Retórica de la modernidad, Lógica de la colonialidad y Gramática de la descolonialidad. Buenos Aires: Del Signo.

Mouffe, Chantal (2000): "Politics and passions. The stakes of democracy" Ethical Perspectives, 7. 2-3: 146-150

NussBaum, Martha (2005): El conocimiento del amor.Ensayos sobre filosofía y literatura. Madrid: Antonio Machado.

(2008): Paisajes del pensamiento. La inteligencia de las emociones. Barcelona: Paidos. (2012): Political Emotions: The Public Psychology of a Decent Society (Borrador) [http://politicalscience.stanford.edu/sites/default/files/workshop-materials/pt_nussbaum.pdf]

PeIrCE, C.A. (1965): Collected Papers (Vol. 1-8). Cambridge: Harvard University Press.

Peñamarin, Cristina (2008): “¿Hay vida en el espacio público mediatizado?”. CIC. Cuadernos de información y comunicación, 13: 61-78.

2009: "Comunicación y territorizalización. Extraños en Abu Ghraib" I/C Revista científica de información y comunicación, 6: 319-336. 
2011: en Dávila, Andrés "Dilemas del conocimiento, la comunicación y la esfera pública global" en La idea de crisis revisitada: variaciones e interferencias. Bilbao: Universidad del País Vasco.

Rosas, Omar (2011): "La estructura disposicional de los sentimientos". Ideas y valores. 145: 5-31.

SAIZ EcheZARreta, Vanesa (2007): "Disposiciones emocionales en las fronteras de la comunicación intercultural” en Valbuena, F. Eric Berne. Teórico de la comunicación. Madrid: Edipo.

- (2008): "Resolución de la distancia moral a través de la mediación experta de las ONGD” en CIC Cuadernos de Información y Comunicación.13:.79-106.

(2009): La solidaridad. Espacio de mediación de los sentimientos morales. Análisis de la publicidad de las ONGD. Tesis doctoral. Madrid: Biblioteca Universidad Complutense.

Savan, David (1981): "Peirce's Semiotic Theory of Emotion" en Proceedings of the C.S. Peirce Bicentennial International Congress. (Eds) Kenneth L. Ketner, et al. Lubbock: Texas Tech University Press.

SENNET, Richard (2002): El declive del hombre público. Barcelona: Península.

Stephens, G. Lynn (1981): "Transactions of the Charles S. Peirce Society. 17 (2).131-140.

SURRALlÉS, Alexandre (2005): "Afectividad y epistemología de las ciencias humanas". AIBR. Revista de Antropología Iberoamericana. Noviembre-Diciembre.

VASALLO DE LOPES, María Immacolata (1999): "La investigación en comunicación: cuestiones epistemológicas, teóricas y metodológicas”. Diálogos de la Comunicación, 56. 12-27.

Williams, Raymond (1980): Marxismo y literatura. Barcelona: Península 


\title{
RESUMEN
}

Este artículo propone una aproximación teórica al análisis y a la crítica de las emociones y los sentimientos que se activan en la investigación sobre las acciones colectivas que persiguen un ideal de justicia social. Este trabajo se plantea a partir de una reflexión sobre los lugares comunes en torno a las emociones colectivas que permanecen incuestionados en esta área y elabora un modelo teórico que defiende el carácter mediado de lo afectivo y su caracterización como hábito, a partir de las aportaciones Antonio Damasio y Charles Sanders Peirce. El objetivo de la propuesta es elaborar una noción de disposición afectiva que de cuenta de la relación entre creencias (y valores), estilos de vida y estilos emocionales (o estructuras de sentimiento).

Palabras clave: Semiótica, emociones, disposiciones afectivas, Peirce, cambio social, acción colectiva.

\begin{abstract}
This article proposes a theoretical approach to the analysis and critique of the emotions and feelings that are activated in the research on collective actions to pursue an ideal of social justice. This work arises from a reflection on common concepts about the collective emotions that remain undiscussed in this area, and develops a theoretical model that defends the mediated nature of the affective and its characterization as a habit, from the contributions of Antonio Damasio and Charles Sanders Peirce. The aim of the proposal is to develop a notion of affective disposition that account of the relationship between beliefs (and values), lifestyle and emotional styles (or structures of feeling).
\end{abstract}

Key words: Semiotics, emotions, emotional arrangements, Peirce, social change and collective action.

\section{RÉSUMÉ}

Cet article propose une approche théorique à l'analyse et la critique des émotions et sentiments que sont activés dans la recherche sur les actions collectives afin de poursuivre un idéal de justice sociale. Ce travail parte d'une réflexion sur les lieux communs sur l'émotion collective encore indiscutées dans ce domaine et propose un modèle théorique qui défend la nature médiée par l'affectif et sa caractérisation comme habitude à partir des apports de Antonio Damasio et Charles Sanders Peirce. La proposition vise à développer une idée de la disposition affective que compte la relation entre les croyances et valeurs, style de vie et styles émotionnels (ou structures de sentiment).

Mots clé: Sémiotique, émotions, dispositions émotionnelles, Peirce, changement social et l'action collective. 